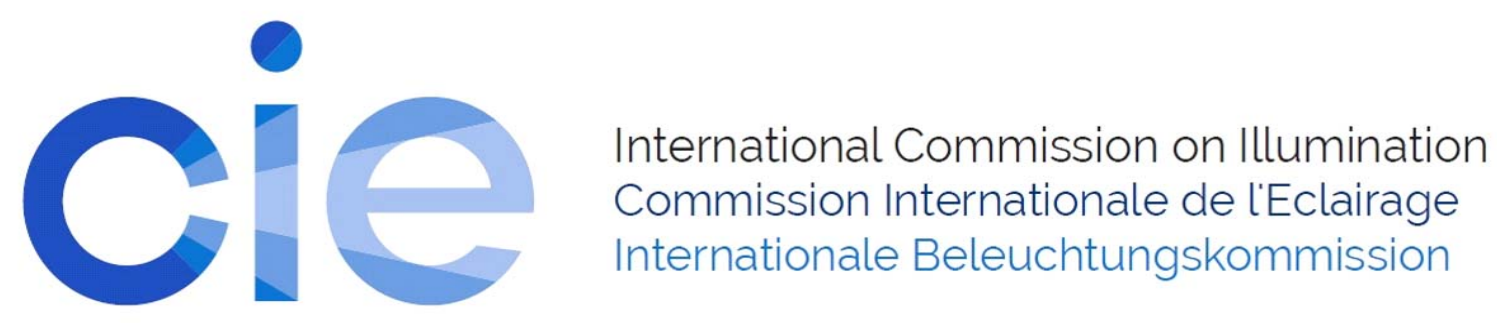

P0169

WHAT ARE YOU LOOKING AT? TESTING NANCY'S RULES FOR PEDESTRIAN INTERACTIONS

\author{
Steve Fotios et al.
}

DOI 10.25039/x46.2019.PO169

from

CIE x046:2019

Proceedings

of the

29th CIE SESSION

Washington D.C., USA, June 14 - 22, 2019

(DOI 10.25039/x46.2019)

The paper has been presented at the 29th CIE Session, Washington D.C., USA, June 14-22, 2019. It has not been peer-reviewed by CIE.

(C) CIE 2019

All rights reserved. Unless otherwise specified, no part of this publication may be reproduced or utilized in any form or by any means, electronic or mechanical, including photocopying and microfilm, without permission in writing from CIE Central Bureau at the address below. Any mention of organizations or products does not imply endorsement by the CIE.

This paper is made available open access for individual use. However, in all other cases all rights are reserved unless explicit permission is sought from and given by the CIE.

CIE Central Bureau

Babenbergerstrasse 9

A-1010 Vienna

Austria

Tel.: +4317143187

e-mail: ciecb@cie.co.at

www.cie.co.at 


\title{
WHAT ARE YOU LOOKING AT? TESTING NANCY'S RULES FOR PEDESTRIAN INTERACTIONS
}

\author{
Fotios, S. ${ }^{1}$, Hamoodh, K. ${ }^{1}$, Clanton, N. ${ }^{2}$ \\ ${ }^{1}$ University of Sheffield, Sheffield, UNITED KINGDOM, ${ }^{2}$ Clanton \& Associates Inc., Boulder, \\ CO, USA. \\ Steve.fotios@sheffield.ac.uk
}

DOI 10.25039/x46.2019.PO169

\begin{abstract}
To establish optimal lighting for inter-personal evaluations between pedestrians it is desirable to know what visual cues are used. An experiment was conducted to test two proposals. One, the widely made assumption (in lighting research) that the face is an important cue. Two, the hierarchy of factors proposed by a lighting designer. This was investigated using category rating with a series of images containing actors embedded into an outdoor scene.
\end{abstract}

Keywords: Pedestrians, Safety, Other People, Visual Cues

\section{Background}

Imagine that you are walking alone along a road after dark and see another pedestrian ahead: at some point a decision is made whether it is safe to keep walking towards the other person or whether they should be avoided. There is a contribution to this decision from visual cues, in which case one aim of road lighting should be to enhance these visual cues.

Lighting guidance and, until recently, most lighting research, has tended to focus on facial recognition, more precisely known as Facial Identity Recognition (FIR). CIE115:2010 states that "high colour rendering contributes to a better facial recognition" and the $\mathrm{P}$ lighting classes add "Additional requirement if facial recognition is necessary". BS EN 13201-2:2015 includes as additional requirements, the SC (semi-cylindrical illuminance) classes for "improving facial recognition".

One aim of past FIR studies has been to determine whether the task is affected by changes in light source spectrum, with some suggesting a significant effect (Knight, 2010, Yao et al 2009) while other experiments have not revealed any effect (Alferdinck et al 2010, Boyce and Rea 1990, Rea et al 2009). These differences can be explained by variations in experimental design (Lin and Fotios 2015, Dong et al 2015), a question not raised in these past studies.

FIR is not the only evaluation we make of other people, nor is it likely to be the most important. Familiar faces are easily recognised even when severely distorted. FIR may be inappropriate because identity does not say anything about intent. There is some reason to consider that the face is an important cue. Identity judgements made when looking at the face only are of similar accuracy to those made when looking at the whole body (whilst body-only judgements are significantly worse) (Burton et al 1999, Hahn et al 2016). Recordings of gaze behaviour using eye tracking whilst looking at images has shown that observers will tend to look at other people if present in a scene with a frequency significantly greater than chance when weighted by area: when looking at other people, viewing time on the face is greater than that on the body (FletcherWatson et al 2008). There is some evidence that approachability judgments are driven by facial expression (Willis et al 2011). A review of ecological validity and procedures concluded that Facial Emotion Recognition (FER) was a more appropriate task for research of lighting effects than FIR, operationalised as the ability to discriminate emotion as conveyed by facial expression (Fotios and Johansson 2019). In three studies using FER to evaluate the effect of changes in lighting (luminance and spectrum), there was no evidence of a significant effect of spectrum (Fotios et al 2015, 2017, Yang and Fotios 2015).

However, FER still uses the face as the target and it is not yet known whether that is the most appropriate visual cue. Before optimal lighting conditions for evaluating other people are 
adopted, there is a need to establish what it is pedestrians tend to look for in other people: we need to know what to light before we can determine how to light it.

This question was discussed within the IESNA committee on Lighting for Outdoor Public Spaces. An anecdotal hierarchy of factors was proposed by committee chair, Nancy Clanton (see Table 1). These are only intended as first-stage ideas. It is recognised that the hierarchy may be different for different observers and there will be interactions between the factors. This article presents an experiment conducted to explore the validity of these proposals.

Table 1 - Proposed hierarchy of factors which influence threat judgements about other pedestrians.

\begin{tabular}{|l|l|l|}
\hline Hierarchy & Factor & Decision \\
\hline 1 & Gender & $\begin{array}{l}\text { Females (or, a male/female combination) are less threatening } \\
\text { than a male. }\end{array}$ \\
\hline 2 & Quantity & One person is more threatening than two (or more) people \\
\hline 3 & $\begin{array}{l}\text { Gaze } \\
\text { direction }\end{array}$ & $\begin{array}{l}\text { A person looking towards me (in apparent act of scoping me } \\
\text { out) is more threatening than a person who is looking } \\
\text { elsewhere. }\end{array}$ \\
\hline 4 & $\begin{array}{l}\text { Walking } \\
\text { direction }\end{array}$ & $\begin{array}{l}\text { A person walking towards me is more threatening than a } \\
\text { person walking away from me. }\end{array}$ \\
\hline
\end{tabular}

\section{Method}

The aim of this experiment was to compare judgements of safety made when looking at photographs of actors embedded in a background outdoor night-time scene. The actors were manipulated to compare the effect of different factors as described in Table 1 and also to determine the influence of face visibility.

These were actors (male and female) posing in front of a green screen, and subsequently embedded into the photographs of an outdoor location at night. Individually, they stood facing towards and away from the camera: for some photographs, the target's face was partially hidden by wearing a hood. Sixteen images were generated, providing combinations of gender, singles and pairs (the pairs being mixed gender in every case), face visibility, direction of light and direction of travel (Figure 1). Due to the small size of features involved, this experiment did not examine gaze direction.

The outdoor scene was a city centre location in Sheffield, the photograph being taken after dark when there were no other people nearby (Figure 2). The photographs were digitally manipulated so that targets were either front lit or backlit, and so that target was sized to resemble location at a distance of approximately $9 \mathrm{~m}$ from the observer. Example images are shown in Figure 3 .

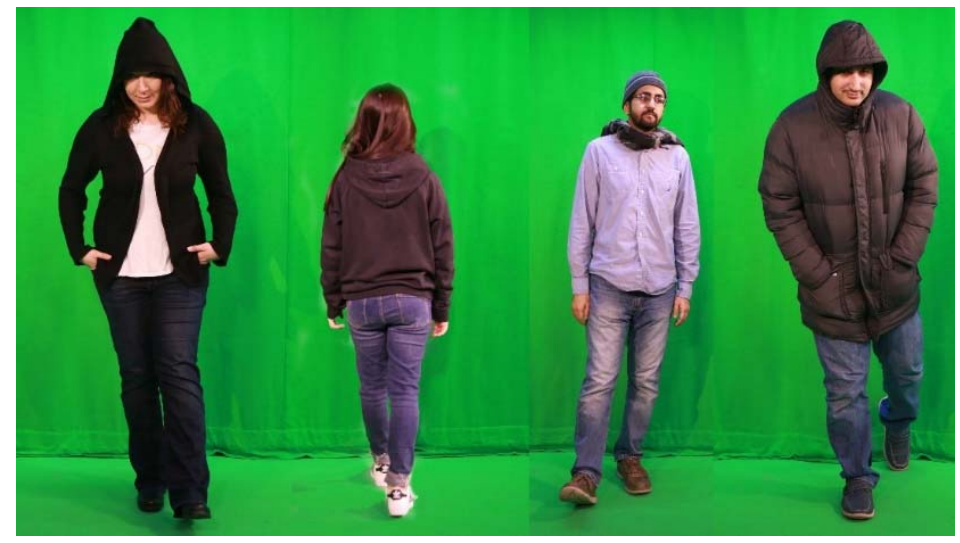

Figure 1 - Examples of the actor photos. These are (from left to right) a single female walking towards the observer and wearing a hood; a single female walking away; a single male walking towards; and a single male walking towards the observer and wearing a hood. 


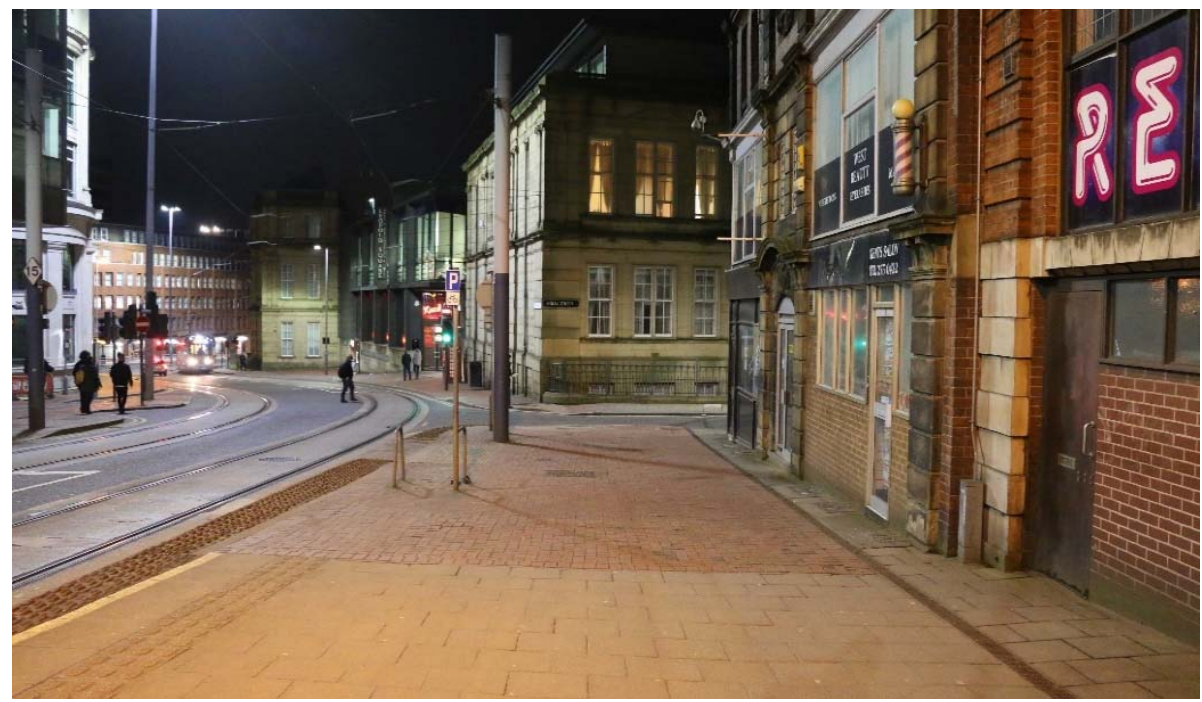

Figure 2 - The outdoor scene into which target actors (Figure 1) were embedded
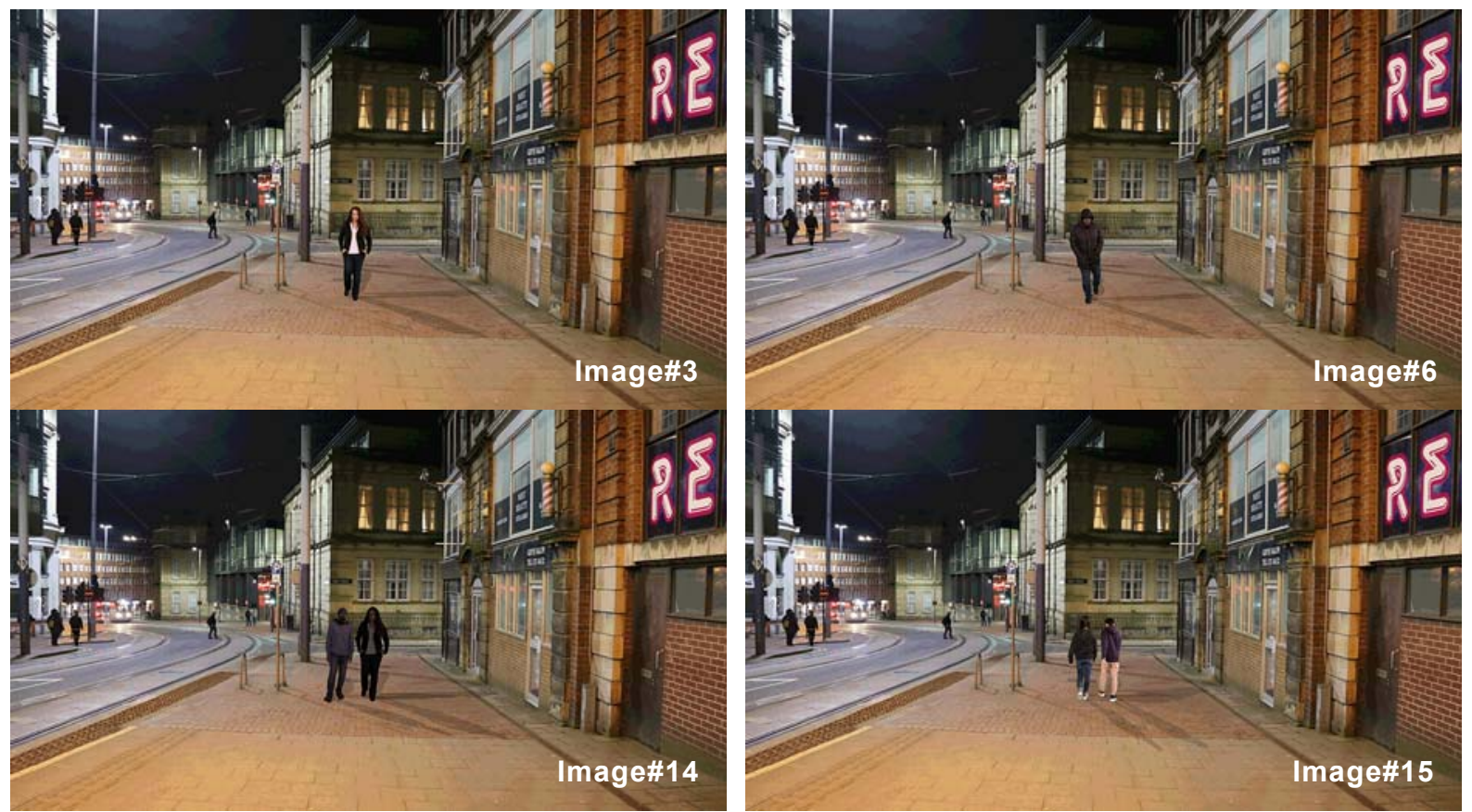

Figure 3 - Examples of the 16 test images. Note that when there were pairs of actors (images \#14 and \#15) they were always mixed male and female.

The images were displayed on a personal computer $(\mathrm{PC})$ screen. In trials, the test participant was seated in a darkened test room. Two test procedures were used, category rating and paired comparison. In the category rating trials the 16 images were observed separately, in a randomised order, for 0.5 seconds each; the degree of safety indicated using a 5-point response scale $(1=$ very unsafe, $5=$ very safe $)$. For the paired comparison trials, the 16 images were evaluated in all 120 possible pairs (together with a further 16 null condition trials): test participants reported which of the two scenes was considered the safer. The results presented here are from 32 test participants (equal balance of male and female, aged 18 to 34 years) who each conducted both procedures. Approval to run this experiment was gained from the ethics committee and each participant provided written consent to participate.

\section{Results}

We present here results and analyses of the category rating data: analyses of the paired comparison data are ongoing. 
The ratings for each scene are shown in Table 2. Median ratings are shown because the distributions were not suggested to be normal according to analyses of dispersion and statistical testing. The purpose of this analysis is not to establish absolute thresholds, as this would be limited by stimulus range bias, but to test differences within each type of variable.

Table 2 - Average ratings of safety for each scene. (Note: $1=$ very unsafe, 5 = very safe).

\begin{tabular}{|l|l|l|l|l|l|l|l|l|}
\hline \multirow{3}{*}{ Image\# } & \multicolumn{9}{|l|}{ Image characteristics } & \multicolumn{3}{l|}{ Rating results } \\
\cline { 2 - 9 } & $\begin{array}{l}\text { No. of } \\
\text { people }\end{array}$ & Gender & $\begin{array}{l}\text { Walk } \\
\text { direction }\end{array}$ & $\begin{array}{l}\text { Light } \\
\text { direction }\end{array}$ & $\begin{array}{l}\text { Wearing } \\
\text { a hood }\end{array}$ & Median & Mean & Std dev \\
\hline 1 & 1 & M & Towards & Front-lit & No & 4.0 & 3.75 & 0.94 \\
\hline 2 & 1 & M & Towards & Front-lit & Yes & 3.5 & 3.28 & 1.01 \\
\hline 3 & 1 & F & Towards & Front-lit & No & 4.0 & 4.31 & 0.73 \\
\hline 4 & 1 & F & Towards & Front-lit & Yes & 4.0 & 3.91 & 0.80 \\
\hline 5 & 1 & M & Towards & Back-lit & No & 3.0 & 3.31 & 1.16 \\
\hline 6 & 1 & M & Towards & Back-lit & Yes & 3.0 & 3.09 & 0.95 \\
\hline 7 & 1 & F & Towards & Back-lit & No & 4.0 & 3.88 & 0.78 \\
\hline 8 & 1 & F & Towards & Back-lit & Yes & 3.0 & 3.34 & 0.99 \\
\hline 9 & 1 & M & Away & Front-lit & No & 4.0 & 4.09 & 0.68 \\
\hline 10 & 1 & M & Away & Front-lit & Yes & 3.0 & 3.25 & 0.97 \\
\hline 11 & 1 & F & Away & Front-lit & No & 4.0 & 4.25 & 0.66 \\
\hline 12 & 1 & F & Away & Front-lit & Yes & 3.0 & 3.22 & 1.02 \\
\hline 13 & 2 & M\&F & Towards & Front-lit & No & 4.0 & 3.72 & 0.94 \\
\hline 14 & 2 & M\&F & Towards & Back-lit & No & 3.0 & 3.19 & 0.88 \\
\hline 15 & 2 & M\&F & Away & Front-lit & No & 4.0 & 4.28 & 0.80 \\
\hline 16 & 2 & M\&F & Away & Back-lit & No & 4.0 & 3.94 & 0.75 \\
\hline
\end{tabular}

The Friedman test suggested significant differences in safety ratings $(p<0.001)$ across all 16 images.

The effect of gender was determined using the Wilcoxon test to compare six pairs of images $(1 \mathrm{v} 3,2 \mathrm{v} 4,5 \mathrm{v} 7,6 \mathrm{v} 8,9 \mathrm{v} 11$ and 10v12), these were chosen so that factors other than gender were consistent. In 3 of 6 cases, this suggested a significant effect $(p<0.01)$ (pairs 1,2,3) with the female target being considered as safer. In all three cases, the target is walking towards the observer so gender should be identifiable. In the remaining three cases (pairs 4,5 and 6), while the results display a tendency for females to be rated as safer, the effect of gender is not significant $(p>0.05)$ : in these three cases, gender identification may have been hindered through the face being partially hidden by the hood (pair 4) and the targets facing away from the observer (pairs 5 and 6). If we can see gender, we tend to consider females as safer than males.

The effect of group size was examined by comparing evaluations of images with two people against images with only one person. For matching conditions (same walking direction, light direction and hand/face visibility), there were two one-person images for each two-person image, and hence ratings of the one-person images were averaged for each test participant. This provided three pairwise comparisons (13 $\vee 1 \& 3 ; 14 \vee 5 \& 7 ; 15 \vee 9 \& 11)$. In each case, the ratings suggest single people to be considered safer than pairs, but this difference was significant only for the first $(p<0.01)$ and second $(p<0.001)$ pairs, but not the third $(p=0.62)$.

The effect of walking direction was determined by testing six pairs of images (1v9, $2 \mathrm{v} 10,3 \mathrm{v} 11$, $4 \mathrm{v} 12,13 \mathrm{v} 15$ and $14 \mathrm{v} 16)$. In the first three pairs, the differences were not suggested to be significant. In the latter three pairs, the differences were significant $(p<0.01)$ suggesting a greater feeling of safety when people are walking away rather than towards.

The effect of light direction was examined through six pairs of images (1v5, 2v6, 3v7, 4v8, $13 \mathrm{v} 14$ and $15 \mathrm{v} 16)$. In all six pairs, the front-lit targets were considered safer than backlit, and this difference was significant in five cases $(p<0.05$ pairs 1 and $6, p<0.01$ pairs 3,4 and 5 ).

The effect of wearing a hood was examined through six pairs of images $(1 \mathrm{v} 2,3 \mathrm{v} 4,5 \mathrm{v} 6,7 \mathrm{v} 8$, $9 \mathrm{v} 10$ and $11 \mathrm{v} 12)$. In all six pairs, the targets not wearing the hood were rated to be safer than 
those wearing a hood, and this difference was significant in five cases $(p<0.05$ pair $2, p<0.01$ pairs $1,4,5,6)$.

\section{Conclusions}

Two experiments were conducted to examine judgements about the apparent threat of other pedestrians, one using category rating and the other paired comparisons, of 16 images observed on a PC screen. Results from the category rating experiment revealed consistent and significant effects of light direction and face visibility: the observed people were considered to be safer when front-lit (rather than back-lit) and when visibility of their face was not impaired by wearing a hood. In those images where gender was more readily apparent (i.e. targets facing the observer), there was a significant effect of gender, with females considered to be safer than males. There was a tendency for single people to be considered safer than pairs and for people walking away to be safer than if walking towards, but the significance of these differences was not consistent.

Results from the paired comparison procedure appear to be similar, but these have yet to be analysed.

Overall, the results suggest that visibility of the face is important: if face visibility is reduced by clothing (wearing a hood) or lighting (back-lit rather than front-lit) then the degree of safety is reduced.

This work should be considered as a pilot study. Further experiments will be conducted to address the limitations, including variation of the background scene, variation in the choice of actors, and giving consideration as to the mode of presentation (e.g. using immersive 3D virtual environment rather than a $2 \mathrm{D}$ target on a PC screen).

\section{Funding}

This work was carried out with support from the Engineering and Physical Sciences Research Council (EPSRC) grant number EP/M02900X/1.

\section{References}

ALFERDINCK, J.W.A.M., HOGERVORST, M.A., VAN EIJK, A.M.J., KUSMIERCZYK, J.T. 2010 Mesopic vision and public lighting - A literature review and a face recognition experiment. TNO-DV C435. Soesterberg ,The Netherlands: TNO.

BOYCE, P.R, REA, M.S. 1990. Security lighting: effects of illuminance and light source on the capabilities of guards and intruders. Lighting Res. Technol., 22, 57-79.

BSI 2016. BS EN 13201-2:2015. Road lighting. Part 2: Performance Requirements. London: BSI.

BURTON, A.M., WILSON, S., COWAN, M., BRUCE, V. 1999. Face recognition in poor-quality video: Evidence from security surveillance. Psychol. Sci., 10(3), 243-248.

CIE 2010. CIE 115:2010. Lighting of Roads for Motor and Pedestrian Traffic. Vienna: CIE.

DONG, M., FOTIOS, S., LIN, Y. 2015. The influence of observation duration and procedure on luminance required for recognition of pedestrian' faces. Lighting Res. Technol, 47(6), 693704.

FLETCHER-WATSON, S., FINDLAY, J.M., LEEKAM, S.R., BENSON, V. 2008. Rapid detection of person information in a naturalistic scene. Perception, 37, 571-583.

FOTIOS, S., CASTLETON, H., CHEAL, C., YANG, B. 2017. Investigating the chromatic contribution to recognition of facial expression. Lighting Res. Technol., 49(2), 243-258.

FOTIOS, S., JOHANSSON, M. 2019. Appraising the intention of other people: Ecological validity and procedures for investigating effects of lighting for pedestrians. Lighting Res. Technol., $51(1), 111-130$. 
FOTIOS, S., YANG, B., CHEAL, C. 2015. Effects of Outdoor Lighting on Judgements of Emotion and Gaze Direction. Lighting Res. Technol., 47(3), 301-315.

HAHN, C.A., O'TOOLE, A.J., PHILLIPS P.J. 2016. Dissecting the time course of person recognition in natural viewing environments. Brit. J Psychol., 107, 117-134.

KNIGHT, C. 2010. Field surveys investigating the effect of lamp spectrum on the perception of safety and comfort at night. Lighting Res. Technol., 42(3), 313-330.

LIN Y., FOTIOS S. 2015. Investigating methods for measuring facial recognition under different road lighting conditions. Lighting Res. Technol., 47(2), 221-235.

REA M.S., BULLOUGH J.D., AKASHI Y. 2009. Several views of metal halide and high pressure sodium lighting for outdoor applications. Lighting Res. Technol., 41(4), 297-314.

WILLIS, M.L., PALERMO, R., BURKE, D. 2011. Judging approachability on the face of it: The influence of face and body expressions on the perception of approachability. Emotion, 11(3), 514-523.

YANG, B., FOTIOS, S. 2015. Lighting and Recognition of Emotion Conveyed by Facial Expressions. Lighting Res. Technol., 47(8), 964-975.

YAO, Q., SUN, Y., LIN, Y. 2009. Research on facial recognition and color identification under $\mathrm{CMH}$ and HPS lamps for road lighting. Leukos, 6(2), 169-178 